\title{
Organochlorine Pesticides and Polychlorinated Biphenyls in Atmospheric Particles Collected in Zagreb, Croatia
}

\author{
Marija Dvoršćak, Ivan Bešlić, Sanja Fingler, Ranka Godec, \\ Krešimir Šega, Želimira Vasilić, and Vlasta Drevenkar*
}

Institute for Medical Research and Occupational Health, Ksaverska c. 2, HR-10000 Zagreb, Croatia

RECEIVED FEBRUARY 5, 2015; REVISED APRIL 3, 2015; ACCEPTED MAY 4, 2015

\begin{abstract}
We studied the occurrence and levels of hexachlorobenzene, $\alpha-, \beta-$, and $\gamma$-hexachlorocyclohexane, 4,4'-DDT, 4,4'-DDE, 4,4'-DDD, and 17 PCBs (six indicator and eleven other toxicologically significant congeners) in $\mathrm{PM}_{10}$ and/or $\mathrm{PM}_{2.5}$ particle fractions collected between 2000 and 2003 and in 2010 at a site in the northern residential part of Zagreb, Croatia. Twenty-four-hour particle samples were collected on glass or quartz microfibre filters from approximately $100 \mathrm{~m}^{3}$ of ambient air per filter. Filters with particles collected over seven consecutive days were combined for ultrasonic extraction with $1: 1$ acetone : $n$-hexane mixture followed by capillary gas chromatography with electron capture detection. In the monitored periods, the mass concentrations of organochlorine compounds in atmospheric particles were characteristic of global environmental pollution and showed a decreasing trend. Local input was observed only for $\gamma$-hexachlorocyclohexane. There were no pronounced seasonal variations in the mass fraction levels of any pesticide or PCB in airborne particles. A decreasing trend in the mass concentrations of some compounds with higher air temperatures was mostly related to the lower particle concentrations in warmer seasons and, consequently, to less particle-bound organochlorine compounds in the atmosphere.
\end{abstract}

Keywords: organochlorine pesticides, $\mathrm{PM}_{10}, \mathrm{PM}_{2.5}$, polychlorinated biphenyls

\section{INTRODUCTION}

Organochlorine $(\mathrm{OC})$ pesticides and polychlorinated biphenyls (PCBs) are widespread semivolatile, lipophilic, and highly persistent environmental pollutants with possible harmful effects on the ecosystem and human health. PCBs include 209 different congeners varying in position and number of chlorine atoms. Their commercial mixtures have been used worldwide since 1929 in many industrial and commercial applications. OC pesticides with hexachlorobenzene (HCB), $\alpha-, \beta-$, and $\gamma$-hexachlorocyclohexane $(\alpha-\mathrm{HCH}, \beta-\mathrm{HCH}$ and $\gamma$-HCH), and 4,4'-DDT [1,1,1,-trichloro-2,2-di(4-chlorophenyl)ethane] as the most prominent representatives, have intensively been used in agriculture and public health since the Second World War. Reflecting concern regarding the harmful effects of increasing residues on the environment, the production and use of PCBs and OC pesticides ceased or were severely restricted in the late 1970s in many countries, including Croatia. Despite restrictions imposed several decades ago, PCBs and OC pesticides are still present in different environmental compartments of biota, air, water, soil, and land and aquatic sediments. Due to their transport over long distances from the primary contaminated areas by circulation of air masses and waters, these pollutants can be found even in regions where they have never been used, e.g., in the Arctic ${ }^{1}$ and the Southern Ocean and Antarctic Peninsula, the northernmost element of mainland Antarctica. ${ }^{2}$ Current environmental levels of PCBs and OC pesticides are primarily the result of their use in the past, but emission sources into environment still exist. ${ }^{3-6}$

The distribution and fate of organochlorine micropollutants in the biosphere depend on a compound's physico-chemical properties as well as on the characteristics of the environment. ${ }^{7}$ As highly hydrophobic compounds, OC pesticides and PCBs strongly bind to soil/sediment particles $^{8}$ which become secondary sources of water, air, and plants pollution and animal and human exposure. An assessment of air-soil exchange of PCBs and OC pesticides across Central and Southern Europe was found to be site-specific and dependent on the physico-chemical properties of specific contaminants, soil properties, historical contamination record and the site's vicinity to sources, and local meteorological conditions. ${ }^{5}$ Soil was confirmed to be a sink

\footnotetext{
* Author to whom correspondence should be addressed. (E-mail: vdreven@imi.hr)
} 
for highly chlorinated PCBs and 4,4'-DDT, whereas for lower chlorinated PCBs and $\alpha-\mathrm{HCH}$, soil tends to be a source of pollution to air.

In the atmosphere, the greatest portion ( $>90 \%$ ) of semivolatile OC pesticides and PCBs is in the gas phase. ${ }^{9-12}$ Their sorption to airborne particulate matter depends on air temperature, compound vapour pressure and particle properties. The more lipophilic highly chlorinated PCBs and DDT-type compounds have a greater tendency to sorb on particles, while less chlorinated PCBs and, for example, HCB exist primarily in vapour phase.

Most studies on OC pesticides and PCBs in the ambient air provide data on their total atmospheric (vapour plus particulate phase) mass concentrations. ${ }^{13-19}$ Literature data on atmospheric concentrations of $\mathrm{OC}$ pollutants adsorbed on the airborne particles are mostly related to the concentrations measured in total suspended particulate matter..$^{9-11,20-24}$ As a complex mixture of organic and inorganic substances, airborne particulate matter (PM) is, however, a key indicator of air pollution brought into the air by a variety of natural and human activities. $^{25}$ The size and composition of particles has been directly linked to their potential for causing adverse human health effects. Of special concern are inhalable coarse particles with an equivalent aerodynamic diameter of $<10 \mu \mathrm{m}\left(\mathrm{PM}_{10}\right)$ and fine particles with an equivalent aerodynamic diameter of $<2.5 \mu \mathrm{m}\left(\mathrm{PM}_{2.5}\right)$. The studies of atmospheric particle-bound OC micropollutants are therefore focused not only on their mass concentrations in the air but also on their particle size distribution. ${ }^{26-33}$

Non-volatile organochlorine compounds such as hepta- and octachlorinated dibenzo- $p$-dioxins and dibenzofurans were found to be more or less completely particle-bound in the atmosphere and, on average, $92 \%$ of these compounds were associated with particles with aerodynamic diameters smaller than $2.9 \mu \mathrm{m} .{ }^{27}$ Particles of that size also contained 60 to $95 \%$ of particle-bound semivolatile less chlorinated congeners, for which significant fractions were present in the gas phase. Concentration levels of PCBs determined in the atmospheric fine particles $\mathrm{PM}_{2.5}$ in the urban environments of Chile were even higher than gas-phase PCBs measured in the atmosphere of other urban areas around the world. ${ }^{28}$ Particle size distributions of total PCBs were found to be bimod$\mathrm{al}^{26}$ with the highest peak in the particle size range between 5.6 and $10.0 \mu \mathrm{m}$, and the second peak in the particle size range between 0.31 and $0.52 \mu \mathrm{m}$. A study of particle size distribution of organic compounds, including OC pesticides and indicator PCBs, in the urban atmosphere indicated their predominant accumulation in the particle fraction $<0.9 \mu \mathrm{m}$ particularly in the cold season. ${ }^{29}$

Knowledge on the occurrence and concentrations of persistent OC pollutants in the air in Croatia is limited. The first data were published for OC pesticides and
PCBs measured in air samples (vapour plus particulate phase) collected in the Zagreb area during $1997^{18}$ and in a follow-up study performed from 1999 to $2001 .{ }^{19}$ Polychlorinated dibenzo- $p$-dioxins and dibenzofurans were analysed in ambient air samples collected in Zagreb from 1997 to $2000 .^{34}$ Within the frame of the APOPSBAL project ("Assessment of the selected POPs in the atmosphere and water ecosystems from the waste generated by warfare in the area of former Yugoslavia"), seven PCB congeners, four $\mathrm{HCH}$-isomers $(\alpha, \beta, \gamma$, and $\delta), \mathrm{HCB}$, and three DDT-type compounds were measured separately in gaseous and particulate ambient air samples collected in 2003 and 2004 in the city of Zadar and at a background site on Mt. Velebit (Zavižan). ${ }^{24,35}$

The aim of our study was to investigate for the first time temporal trends in the occurrence and mass concentrations of particle-bound OC pesticides and PCBs in $\mathrm{PM}_{10}$ and $\mathrm{PM}_{2.5}$ atmospheric particles collected in the northern residential part of the city of Zagreb. The particle samples were collected between 2000 and 2003 and in 2010. The studied compounds were OC pesticides $\mathrm{HCB}, \alpha-, \beta$ - and $\gamma-\mathrm{HCH}, 4,4$ '-DDT and its degradation products 4,4'-DDE [1,1-dichloro-2,2-di(4-chlorophenyl)ethene] and 4,4'-DDD [1,1-dichloro-2,2-di(4-chlorophenyl)ethane], and 17 PCB congeners, including six indicator congeners (PCB-28, PCB-52, PCB-101, PCB-138, PCB-153, PCB-180) and eleven other toxicologically significant congeners (PCB-60, PCB-74, PCB-105, PCB114, PCB-118, PCB-123, PCB-156, PCB-157, PCB-167, PCB-170, PCB-189). The abundance and concentrations of particle-bound OC compounds in air are compared and evaluated with respect to the variations in air temperatures during the sampling periods.

\section{EXPERIMENTAL}

\section{Chemicals}

Organochlorine pesticides were purchased as standards of Pestanal quality from Riedel-de Haën, Sigma-Aldrich Laborchemikalien GmbH, Seelze, Germany. The PCB congener standards were either the products of Riedelde Haën of Oekanal quality or purchased from LGC Promochem (Wesel, Germany) or Ultra Scientific (North Kingstown, RI, USA) as standards of $97 \%$ to $99.8 \%$ purity. Acetone and $n$-hexane for gas chromatography, Suprasolv, and sulphuric acid, p.a., 95-97\%, were from Merck KGaA, Darmstadt, Germany.

\section{Sampling of Airborne Particles}

Samples of $\mathrm{PM}_{10}$ and/or $\mathrm{PM}_{2.5}$ fractions of atmospheric particles were collected daily from October 2000 to December 2003, from January to March 2010, and from June to July 2010 at a site in the northern residential 
part of the Zagreb city using sampling equipment designed and manufactured at the Institute for Medical Research and Occupational Health. The suitability of the self-constructed sampling equipment regarding the European Norm EN 12341:1998 ${ }^{36}$ was tested and confirmed in a previous study of $\mathrm{PM}_{10}$ and $\mathrm{PM}_{2.5}$ levels in urban part of Zagreb by comparison with a reference low volume sampler manufactured by Ingenieurbüro Sven Leckel (Berlin, Germany). ${ }^{37}$

The sampler inlets were set at $1.5 \mathrm{~m}$ above the ground level at a distance of approximately $15 \mathrm{~m}$ away from a road busy with traffic. Twenty-four-hour samples of particle fractions were collected on two glass fibre GF/A (2000 to 2003 period) or quartz microfibre (2010) filters (Whatman, UK), $90 \mathrm{~mm}$ in diameter, in parallel, from approximately $100 \mathrm{~m}^{3}$ of ambient air per filter at the average air flow rate of $72 \mathrm{~L} \mathrm{~min}^{-1}$. The coarse particles were removed by an inertial impactor. The samples were wrapped in aluminium foil and kept at $-18{ }^{\circ} \mathrm{C}$, until analysis.

Prior to use, the quartz filters were heated at $900{ }^{\circ} \mathrm{C}$ for $3 \mathrm{~h}$. The glass and quartz filters were conditioned (prior and after the sampling) according to European standard sampling regulations EN 12341:1998 ${ }^{36}$ and EN 14907:2005 $5^{38}$ and then weighed. A microbalance Mettler Toledo MX5 (Mettler Toledo, Columbus, OH, USA) was used for mass determination of $\mathrm{PM}_{10}$ and $\mathrm{PM}_{2.5}$.

Data on ambient air temperature and pressure during the sampling periods were obtained from Meteorological and Hydrological Service of Croatia. The average weekly air temperatures ranged from -7.6 to 25.8 ${ }^{\circ} \mathrm{C}$ (median $11.1^{\circ} \mathrm{C}$ ) in the period from October 2000 to December 2003 , from -4.3 to $6.5^{\circ} \mathrm{C}$ (median $0.8{ }^{\circ} \mathrm{C}$ ) during 2010 winter months (January-March), and from 16.1 to $27.3{ }^{\circ} \mathrm{C}$ (median $22.8^{\circ} \mathrm{C}$ ) during 2010 spring/ summer months (June-July).

\section{Sample Analysis}

Fourteen filters with particle samples collected during seven consecutive days were extracted together for three consecutive times with $60 \mathrm{~mL}$ of $1: 1$ acetone: $n$-hexane mixture in an ultrasonic bath for $15 \mathrm{~min}$ and finally washed with an additional $10 \mathrm{~mL}$ of extracting solvent. The combined extracts were evaporated to dryness under a gentle stream of nitrogen. Immediately before gas chromatographic analysis, the dry residue was dissolved in $1.00 \mathrm{~mL}$ of $n$-hexane and washed with $1 \mathrm{~mL}$ of concentrated sulphuric acid. The $n$-hexane layer was separated and analysed in parallel on two gas chromatographic columns of different polarity using a Varian 3380 and a Varian CP3800 gas chromatograph (Varian, Walnut Creek, CA, USA). Both chromatographs were equipped with a split/splitless injector and a ${ }^{63} \mathrm{Ni}$ electron capture detector (ECD). The fused silica columns $(60 \mathrm{~m} \times 0.25 \mathrm{~mm}$ i.d., film thickness $0.25 \mu \mathrm{m})$ used were a Rtx-5MS column (Restek, Bellefonte, PA, USA) in the former chromatograph and a DB-17MS (J\&W Scientific, Agilent Technologies, Folsom, CA, USA) column in the latter chromatograph. The temperature of both columns was programmed from $90{ }^{\circ} \mathrm{C}$ (with $1 \mathrm{~min}$ hold) up to $180{ }^{\circ} \mathrm{C}$ at $30{ }^{\circ} \mathrm{C} \mathrm{m^{-1 }}$ with a hold of $1 \mathrm{~min}$, from $180{ }^{\circ} \mathrm{C}$ to $240{ }^{\circ} \mathrm{C}$ at $2{ }^{\circ} \mathrm{C} \mathrm{min}{ }^{-1}$ with a hold of $20 \mathrm{~min}$, and finally from $240{ }^{\circ} \mathrm{C}$ to $280{ }^{\circ} \mathrm{C}$ at $5{ }^{\circ} \mathrm{C} \mathrm{min}{ }^{-1}$ with a hold of $11 \mathrm{~min}$. The injector temperature was $270{ }^{\circ} \mathrm{C}$ for sample analysis on Rtx-5MS column (splitless injection for $45 \mathrm{~s}$ ) and $250{ }^{\circ} \mathrm{C}$ for sample analysis on DB-17MS column (splitless injection for $30 \mathrm{~s}$ ). The sample volume injected was $2 \mu \mathrm{L}$. The detector temperature was $350{ }^{\circ} \mathrm{C}$. Nitrogen was used as the make-up

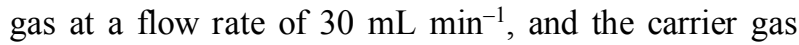
was helium (99.9999\% pure) at a flow rate of $1.2 \mathrm{~mL}$ $\mathrm{min}^{-1}$ and $1.0 \mathrm{~mL} \mathrm{m^{-1 }}$ for analysis on the Rtx-5MS and DB-17MS column, respectively.

\section{Data Validation}

Organochlorine compounds extracted from atmospheric particles were quantified using the multipoint calibration curves obtained by analysis of standard solutions prepared in $n$-hexane. Reagent blanks and blank samples of pure glass or quartz microfiber filters were treated and analysed in the same manner as the real samples. Organochlorine analytes or interfering impurities were not detected in any of the blank samples. The concentrations of compounds detected in the particle samples were calculated as the mean values of the results obtained on two different gas chromatographic columns. Only the peaks observed on both columns were evaluated. The results were corrected for extraction recoveries and recalculated to normal conditions.

The ultrasonic extraction procedure was not uniformly efficient but still satisfied for trace enrichment of different OC compounds from atmospheric particles. The recoveries were determined during each sampling period by analysis of filters with known mass of collected particles spiked with OC analytes at nanogram per milligram levels. At mass fractions of 0.05 to $1.05 \mathrm{ng}$ $\mathrm{mg}^{-1}$, the recoveries of OC pesticides ranged from $36 \%$ for $\mathrm{HCB}$ to $87 \%$ for 4,4 -DDD (RSD 7 to $32 \%$ ). The recoveries of $\mathrm{PCB}$ congeners, determined at single congener mass fractions ranging from 0.05 to $0.67 \mathrm{ng} \mathrm{mg}^{-1}$, were 56 to $97 \%$ (RSD 9 to $31 \%$ ). The lowest recovery was obtained for PCB-101 and the highest for PCB-114. Detection limits obtained by analysis of $1 \mathrm{~mL}$ extracts of particles collected from a total of about $1400 \mathrm{~m}^{3}$ of air ranged from $0.02 \mathrm{pg} \mathrm{m}^{-3}$ for $\alpha-\mathrm{HCH}$ and PCB-180 to $0.2 \mathrm{pg} \mathrm{m}^{-3}$ for $\beta-\mathrm{HCH}$.

All statistical analyses were performed using Statistica 12 (StatSoft Inc., Tulsa, OK, USA) at a significance level of $p<0.05$. 


\section{RESULTS AND DISCUSSION}

\section{Optimization of Sampling Procedure}

Due to the low levels of OC pesticides and PCBs in atmospheric particles, the sensitivity of their determination greatly depends on the mass of particle samples. The mass of particles collected on a glass or quartz microfiber filter from $100 \mathrm{~m}^{3}$ of air during a period of 24 hours was too low for a reliable and sensitive analysis of particle-bound OC pesticides and PCB congeners. The collection of particles from larger air volumes, e.g. from $700 \mathrm{~m}^{3}$ of air drawn through a filter during seven consecutive days, failed due to the observed volatilisation losses of all measured organochlorine pesticides as well as of some PCB congeners (PCB-28, PCB-52 and PCB-101) leading to an underestimation of particlebound OC compounds. This finding is in accordance with literature data showing that high amounts of PCBs may volatilise from fine particles during aerosol sampling and that the volatilisation losses strongly depend on partial pressure of individual congeners and air temperature. ${ }^{28}$

To minimise volatilisation losses and achieve sufficiently high determination sensitivity of OC pollutants associated with $\mathrm{PM}_{10}$ and $\mathrm{PM}_{2.5}$ particle fractions, the present study combined two sets of seven filters with one-day particle samples collected during a week for ultrasonic extraction. Thus, the weekly particle samples were collected from a total air volume of approximately $1400 \mathrm{~m}^{3}$.

\section{Distribution of OC Pollutants in $\mathbf{P M}_{2.5}$ and $\mathbf{P M}_{10}$ Fractions}

Possible differences in the distribution of OC pollutants in airborne particles of different size were tested by analysis of pesticides and six indicator PCBs in 30 simultaneously collected weekly samples of $\mathrm{PM}_{2.5}$ and $\mathrm{PM}_{10}$ in the period from October 2000 to May 2001 (Table 1). Air concentrations of compounds associated with two different particle fractions were statistically compared using the Wilcoxon matched pairs test. The concentrations were not significantly different $(p>0.05)$ indicating that the pollutants were mostly contained in the $\mathrm{PM}_{2.5}$ fraction. Since the results of $\mathrm{PM}_{2.5}$ and $\mathrm{PM}_{10}$ analysis were statistically comparable, the study was continued by sampling and analysis of only one particle fraction: $\mathrm{PM}_{10}$ in 2001 to 2003 and $\mathrm{PM}_{2.5}$ in 2010.

\section{Temporal Trends in Concentration of OC Pesticides and PCBs in Particles in Air}

The mass concentrations of particle-bound OC pesticides and $\mathrm{PCB}$ congeners in weekly samples of $\mathrm{PM}_{10}$ collected between 2000 and 2003 and in $\mathrm{PM}_{2.5}$ collected in 2010 are summarised in Tables 2 and 3.

OC pesticides were analysed in a total of 183 weekly particle samples (Table 2 ). The most frequently detected pesticides were $\mathrm{HCH}$ isomers $(\gamma-\mathrm{HCH}$ in $96 \%$, $\beta-\mathrm{HCH}$ in $83 \%$, and $\alpha-\mathrm{HCH}$ in $73 \%$ of samples), followed by $4,4^{\prime}$-DDT and 4,4'-DDE determined in $82 \%$

Table 1. Mass concentrations of OC pesticides and six PCB indicator congeners in weekly samples of $\mathrm{PM}_{10}$ and $\mathrm{PM}_{2.5}$ particle fraction collected from October 2000 to May 2001

\begin{tabular}{|c|c|c|c|c|c|c|}
\hline \multirow{3}{*}{ Compound } & \multicolumn{3}{|c|}{$\mathrm{PM}_{10}(N=30)$} & \multicolumn{3}{|c|}{$\mathrm{PM}_{2.5}(N=30)$} \\
\hline & \multirow{2}{*}{$n$} & \multicolumn{2}{|c|}{$\gamma / \mathrm{pg} \mathrm{m}^{-3}$} & \multirow{2}{*}{$n$} & \multicolumn{2}{|c|}{$\gamma / \mathrm{pg} \mathrm{m}^{-3}$} \\
\hline & & Range $^{(\mathrm{a})}$ & $\operatorname{Median}^{(a)}$ & & Range $^{(a)}$ & $\operatorname{Median}^{(\mathrm{a})}$ \\
\hline HCB & 18 & $0.89-27.8$ & 6.34 & 16 & $0.96-22.8$ & 6.03 \\
\hline$\alpha-\mathrm{HCH}$ & 12 & $0.74-3.80$ & 2.10 & 11 & $0.44-4.64$ & 1.46 \\
\hline$\beta-\mathrm{HCH}$ & 27 & $3.74-42.2$ & 19.0 & 27 & $5.84-59.2$ & 27.3 \\
\hline$\gamma-\mathrm{HCH}$ & 27 & $2.38-14.6$ & 6.02 & 30 & $2.34-12.9$ & 6.33 \\
\hline 4,4'-DDE & 27 & $1.91-34.8$ & 7.12 & 25 & $0.71-33.1$ & 7.07 \\
\hline 4,4'-DDD & 9 & $1.09-16.6$ & 10.8 & 11 & $1.99-25.0$ & 8.69 \\
\hline 4,4'-DDT & 25 & $1.35-26.7$ & 9.56 & 22 & $3.26-43.3$ & 9.27 \\
\hline PCB-28 & 13 & $2.22-59.5$ & 11.6 & 10 & $1.65-42.9$ & 21.4 \\
\hline PCB-52 & 0 & & & 0 & & \\
\hline PCB-101 & 2 & $12.4-32.8$ & 22.6 & 2 & $4.63-21.8$ & 13.2 \\
\hline PCB-138 & 18 & $0.87-9.53$ & 2.76 & 20 & $0.56-19.6$ & 2.89 \\
\hline PCB-153 & 11 & $2.63-10.5$ & 4.30 & 8 & $2.74-14.1$ & 4.64 \\
\hline PCB-180 & 0 & & & 0 & & \\
\hline$\sum \mathrm{PCB}^{(\mathrm{b})}$ & 25 & $0.87-70.6$ & 8.07 & 24 & $1.00-55.0$ & 5.38 \\
\hline
\end{tabular}

$N$ - number of analysed samples, $n$ - number of positive samples.

(a) ranges and median values apply to positive samples

(b) sum of the six indicator PCBs. 


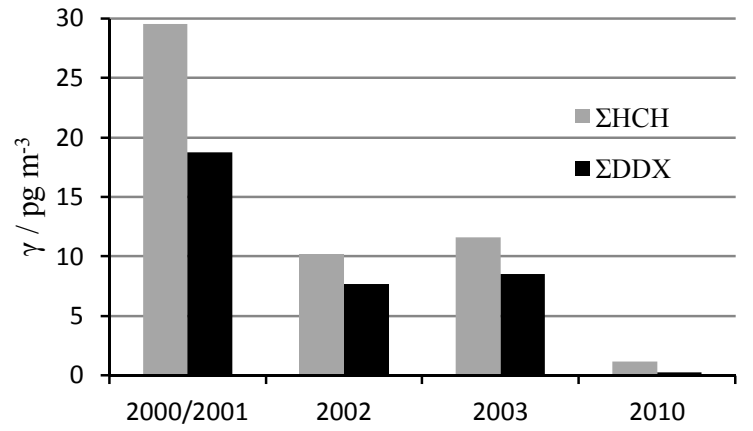

Figure 1. Comparison of the median mass concentrations of the sum of $\mathrm{HCH}$ isomers $(\Sigma \mathrm{HCH})$ and DDT-type compounds ( $\Sigma$ DDX) measured in weekly samples of $\mathrm{PM}_{10}$ particle fraction in 2000/2001, 2002, and 2003 and samples of $\mathrm{PM}_{2.5}$ particle fraction in 2010. Median values apply to all analysed samples (for number of analysed samples $N$ see Table 2).

and $80 \%$ of samples. HCB was detected in $56 \%$ and $4,4^{\prime}$-DDD in $52 \%$ of samples. HCB was also among the most frequently detected pesticides in 2002 , with some of the highest concentrations and with a presence in more than $80 \%$ of samples. In 2010 , the mass concentrations and abundance in air particles were for most pesticides considerably lower than in earlier years. It should be noted that in $40 \%$ of the particle samples analysed between 2000 and 2010, $\beta$-HCH was the dominant $\mathrm{HCH}$ isomer accounting for $\geq 50 \%$ of the total $\mathrm{HCH}$ isomer mass concentrations. This might be a consequence of its much lower vapour pressure favouring sorption to airborne particles, and higher environmental persistence compared to other $\mathrm{HCH}$ isomers.

The significantly decreasing trend in the mass concentrations of the most frequently detected pesticides is illustrated in Figure 1, which compares the median values of the sum of three $\mathrm{HCH}$ isomer mass concentrations $(\Sigma \mathrm{HCH})$ and DDT-type compounds ( $\mathrm{DDDX}$ ) measured in weekly samples of particle fractions collected in 2000/2001, 2002, 2003, and 2010. Since concentration data were missing for a number of years within the investigated period, modelling was performed in order to get a better insight in concentration decreasing process. Trend estimation over the 2000 to 2010 period shows an exponential diminishing rate of $50 \%$ every 17 and 20 months for $\Sigma \mathrm{HCH}$ and $\Sigma \mathrm{DDX}$, respectively $\left(r^{2}>0.95\right)$. The slight increase of $\Sigma \mathrm{HCH}$ and $\Sigma$ DDX in 2003 as compared to 2002 is not significant and falls within measurement uncertainty. The comparison of OC pesticide concentrations in air samples collected in Zagreb at the same location from June 1999 to February $2000^{19}$ and from June 2007 to June $2008^{39}$ also revealed a decreasing trend in concentrations of $\mathrm{HCH}$-isomers and DDT-type compounds.

The ratio of $\alpha-\mathrm{HCH} / \gamma-\mathrm{HCH}$ mass concentrations is an indicator of recent $v s$. old usage of $\mathrm{HCH}$ isomers and the distance from the input sources over which the $\mathrm{HCH}$ isomers may have been transported. ${ }^{6,22}$ Both isomers were detected in 133 samples, only $\gamma-\mathrm{HCH}$ in 42 samples and only $\alpha-\mathrm{HCH}$ in only one sample out of 183 particle samples analysed in this paper. In most (80\%) of particle samples containing both isomers, the $\alpha-\mathrm{HCH} / \gamma-\mathrm{HCH}$ ratio was lower than one $(0.01$ to 0.98 , median 0.52) indicating a higher input of the $\gamma-\mathrm{HCH}$ into the atmosphere. A recent input of $\gamma-\mathrm{HCH}$ was also observed in air samples collected at the same sampling location from June 1999 to February $2000^{19}$ and from June 2007 to June $2008^{39}$. $\alpha-\mathrm{HCH}$ and $\gamma-\mathrm{HCH}$ were detected in all of the analysed samples and the median of their mass concentration ratio was 0.2 in the former and 0.14 in the latter period. This may partly be a consequence of the local preferable usage of a lindane formulation in the past (banned in Croatia in 2005) containing $>90 \%$ of $\gamma-\mathrm{HCH}$ as the active ingredient, but also of the new inputs via atmospheric transport from remote areas. On the other hand, in 27 (20\%) particle samples containing both isomers, the $\alpha-\mathrm{HCH} / \gamma-\mathrm{HCH}$ ratio was $\geq 1$ (1.01 to 8.45 , median 1.34). According to Dvorská et al., ${ }^{6}$ classifying the values of the $\alpha-\mathrm{HCH} / \gamma$ $\mathrm{HCH}$ ratio into four groups may reveal more detailed

Table 2. Mass concentrations of OC pesticides measured in weekly samples of $\mathrm{PM}_{10}$ particle fraction collected in 2000/2001, 2002 and 2003 and $\mathrm{PM}_{2.5}$ fraction collected in 2010

\begin{tabular}{|c|c|c|c|c|c|c|c|c|c|c|c|c|}
\hline \multirow{3}{*}{ Compound } & \multicolumn{3}{|c|}{ Year 2000/2001, $N=57$} & \multicolumn{3}{|c|}{ Year $2002, N=52$} & \multicolumn{3}{|c|}{ Year 2003, $N=52$} & \multicolumn{3}{|c|}{ Year $2010, N=22$} \\
\hline & \multirow{2}{*}{$n$} & \multicolumn{2}{|c|}{$\gamma / \mathrm{pg} \mathrm{m}^{-3}$} & \multirow{2}{*}{$n$} & \multicolumn{2}{|c|}{$\gamma / \mathrm{pg} \mathrm{m}^{-3}$} & \multirow{2}{*}{$n$} & \multicolumn{2}{|c|}{$\gamma / \mathrm{pg} \mathrm{m}^{-3}$} & \multirow{2}{*}{$n$} & \multicolumn{2}{|c|}{$\gamma / \mathrm{pg} \mathrm{m}^{-3}$} \\
\hline & & Range $^{(a)}$ & Median $^{(a)}$ & & Range $^{(a)}$ & Median $^{(a)}$ & & Range $^{(a)}$ & Median $^{(a)}$ & & Range $^{(a)}$ & Median $^{(a)}$ \\
\hline $\mathrm{HCB}$ & 19 & $0.89-27.7$ & 6.81 & 44 & $0.28-24.5$ & 7.49 & 30 & $0.04-10.4$ & 1.61 & 10 & $0.55-7.54$ & 3.30 \\
\hline$\alpha-\mathrm{HCH}$ & 39 & $0.74-25.2$ & 7.38 & 50 & $0.02-15.6$ & 1.87 & 41 & $0.83-6.89$ & 2.73 & 4 & $0.22-0.79$ & 0.60 \\
\hline$\beta-\mathrm{HCH}$ & 54 & $1.99-42.2$ & 15.83 & 46 & $0.48-28.8$ & 5.14 & 41 & $1.45-17.6$ & 4.64 & 10 & $0.15-24.3$ & 4.49 \\
\hline$\gamma-\mathrm{HCH}$ & 54 & $1.60-23.9$ & 9.03 & 52 & $0.31-19.0$ & 3.22 & 50 & $0.10-15.1$ & 4.83 & 19 & $0.04-2.71$ & 0.62 \\
\hline 4,4'-DDE & 54 & $0.60-40.9$ & 7.69 & 45 & $0.07-17.0$ & 3.41 & 38 & $0.26-29.2$ & 3.35 & 10 & $0.13-1.84$ & 0.99 \\
\hline 4,4'-DDD & 34 & $0.74-27.0$ & 10.65 & 21 & $1.18-20.7$ & 8.81 & 39 & $0.27-14.3$ & 4.99 & 1 & 2.60 & 2.60 \\
\hline 4,4'-DDT & 52 & $0.50-26.7$ & 6.41 & 41 & $0.12-8.39$ & 3.95 & 52 & $0.20-11.5$ & 2.47 & 5 & $0.40-1.66$ & 0.55 \\
\hline
\end{tabular}

$N$ - number of analysed samples, $n$ - number of positive samples.

(a) ranges and median values apply to positive samples. 

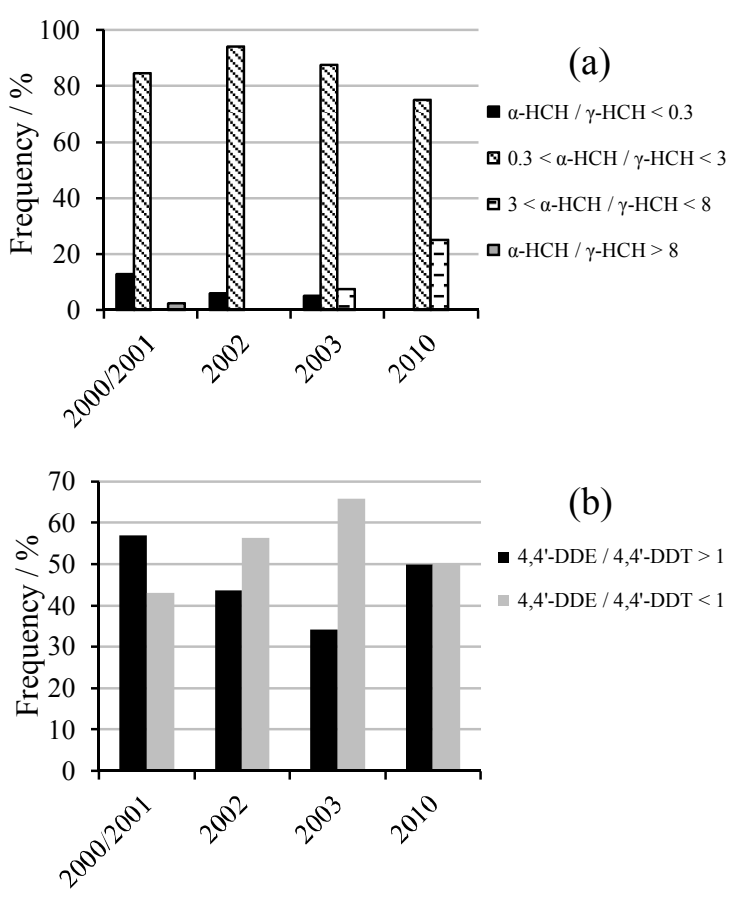

Figure 2. Ratios of $\alpha-\mathrm{HCH}$ to $\gamma-\mathrm{HCH}$ (a) and 4,4 '-DDE to 4,4'-DDT (b) mass concentrations measured in weekly samples of $\mathrm{PM}_{10}$ particle fraction in 2000/2001, 2002, and 2003 and samples of $\mathrm{PM}_{2.5}$ particle fraction in 2010.

information on recent and old usage of $\mathrm{HCH}$ isomers. A $\alpha-\mathrm{HCH} / \gamma-\mathrm{HCH}$ ratio $<0.3$ indicates emissions of nondegraded lindane, $0.3<\alpha-\mathrm{HCH} / \gamma-\mathrm{HCH}<3$ of aged lindane, $3<\alpha-\mathrm{HCH} / \gamma-\mathrm{HCH}<8$ of fresh technical $\mathrm{HCH}$ (containing predominantly $\alpha-\mathrm{HCH}$ ) and $\alpha-\mathrm{HCH} / \gamma-\mathrm{HCH}$ $>8$ of aged technical HCH. As shown in Figure 2, $\alpha-\mathrm{HCH} / \gamma-\mathrm{HCH}$ ratios classified according to this scheme for particle samples collected between 2000 and 2010 indicated the predominant emission of aged lindane in all four sampling periods. The frequency of particle samples classified in the four groups by the $\alpha-\mathrm{HCH} / \gamma-\mathrm{HCH}$ ratio was calculated in relation to the number of samples containing both isomers: 39 samples in 2000/2001, 50 samples in 2002, 40 samples in 2003 and 4 samples in 2010. The emission of non-degraded lindane, although to a lesser extent than aged lindane, was indicated by both $\alpha-\mathrm{HCH} / \gamma-\mathrm{HCH}$ ratios lower than 0.3 and a number of samples containing only $\gamma$-isomer in all of the sampling periods. An occasional input of fresh $\mathrm{HCH}$ was indicated in three samples collected in 2003 and one sample collected in 2010. A $\alpha-\mathrm{HCH} / \gamma-\mathrm{HCH}$ ratio higher than 8 , indicating the input of aged technical $\mathrm{HCH}$, was detected only in one sample from 2001.

The ratio of 4,4'-DDE/4,4'-DDT mass concentrations is often used as an indicator of recent $4,4^{\prime}$-DDT input into the atmosphere. In the period from 2000 to 2010 , both compounds were detected in $132(72 \%)$ particle samples. The samples were characterised by a wide range of 4,4'-DDE/4,4'-DDT mass concentration ratios (0.04 to 19.3 , median 0.97). In 61 samples, the ratio was higher than one (median 1.90) indicating an old input of 4,4'-DDT, which was largely converted to 4,4'-DDE. However, in 71 samples the ratio was lower than one (median 0.63 ) indicating that there had been a recent input of 4,4'-DDT into the atmosphere most likely as a consequence of the long-range transport from the tropics and other areas where it may still be in use as well as from remote point sources in areas contaminated by accidental spills. ${ }^{3} 4,4^{\prime}$-DDE/4,4'-DDT ratios in the particle samples collected during the four sampling periods between 2000 and 2010 are compared in Figure 2. The percentage of samples with a prevalence of 4,4 -DDT was significant in all periods and ranged from $43 \%$ in $2000 / 2001$ to $65 \%$ in 2003 . This finding was in good agreement with low 4,4'-DDE/4,4'-DDT ratios found in air samples collected at the same location in 1999 and 2000 (median value 0.8$)^{19}$ and in pine needle samples collected in Zagreb in 2006 (median value 0.55$){ }^{40}$

Table 3 shows the mass concentrations of particlebound PCB congeners measured in air in 2000/2001, 2002, 2003 and 2010. The number of samples analysed for six indicator PCBs was 183, while the other 11 congeners were analysed in a total of 153 samples. The most frequently detected PCBs were PCB-28 (68 \% of samples), PCB-138 and PCB-153 (51\% of samples), PCB-52 (50 \% of samples), PCB-60 and PCB-118 (48\% of samples), and PCB-101 (45\% of samples). PCB-74, PCB-157 and PCB-180 were present in about a third of samples and PCB-114 and PCB-170 in about a quarter samples. Detection frequency of other congeners ranged from $19 \%$ for PCB-156 to only $4 \%$ for PCB189. In the period from 2000 to 2003 , the highest mass concentrations were determined for $\mathrm{PCB}-28$ followed by PCB-101. These two congeners together with PCB52 largely contributed to the sum of six indicator congeners detected in all air samples collected at the same location in $2000 .{ }^{41}$ Compared to the air samples, the PCB levels in the airborne particle samples were considerably lower. The mass concentrations of PCBs in air, expressed as the sum of six PCB indicator congeners, ranged from 10.7 to $577.0 \mathrm{pg} \mathrm{m}^{-3}$ and in the particles in air from $0.12 \mathrm{pg} \mathrm{m}^{-3}$ to $111 \mathrm{pg} \mathrm{m}^{-3}$. Minimum, maximum and median values of mass concentration sums of six indicator PCBs and of 17 PCBs measured in weekly samples of airborne particles during four sampling periods between 2000 and 2010 are compared in Figure 3 . The presented results clearly indicate a significant decrease in mass concentrations of all congeners between 2003 and 2010 . 

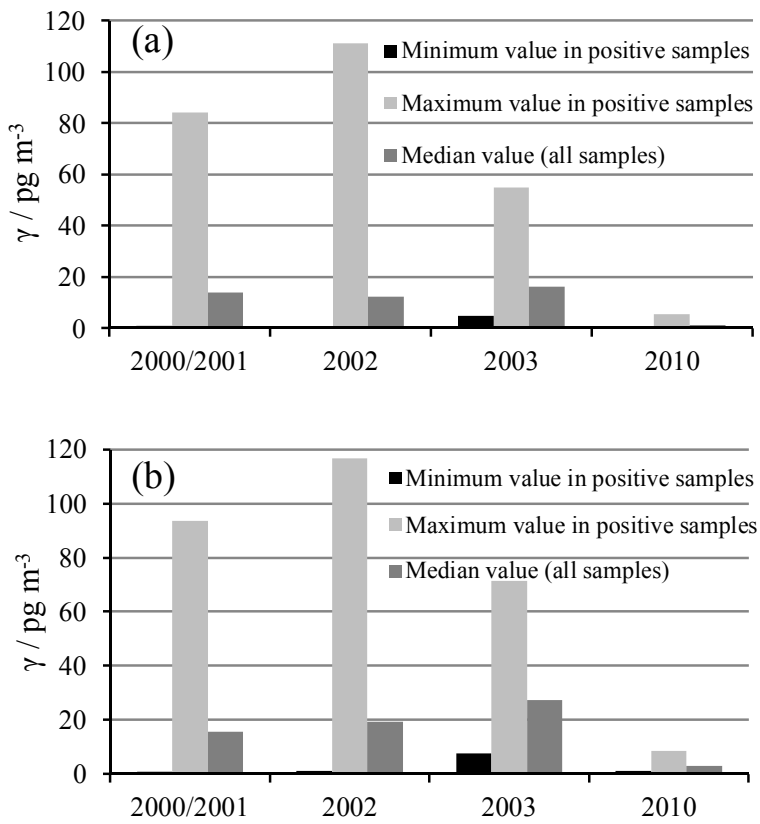

Figure 3. Comparison of mass concentration sums of six PCB indicator congeners (a) and 17 PCB congeners measured in weekly samples of $\mathrm{PM}_{10}$ particle fraction in 2000/2001, 2002, and 2003 and samples of $\mathrm{PM}_{2.5}$ particle fraction in 2010 (b). For number of analysed $(N)$ and positive $(n)$ samples see Table 3.
Compared to urban areas in other countries, the mass concentrations of particle-bound indicator PCBs measured in Zagreb in 2010 were lower than those measured in $\mathrm{PM}_{(>0.95-30)}$ in Thessaloniki (northern Greece) in the summer of 2008 (median mass concentrations from 0 pg m${ }^{-3}$ for PCB-138 to $86.4 \mathrm{pg} \mathrm{m}^{-3}$ for PCB-180) ${ }^{29}$ and similar to those measured in $\mathrm{PM}_{2.5}$ and $\mathrm{PM}_{10}$ in China's metropolis Taiyuan in December 2006 (maximum mass concentrations from $1.3 \mathrm{pg} \mathrm{m}^{-3}$ for PCB-118 to $2.4 \mathrm{pg} \mathrm{m}^{-3}$ for PCB-28 in $\mathrm{PM}_{2.5}$ and from $0.8 \mathrm{pg} \mathrm{m}^{-3}$ for PCB-180 to $10 \mathrm{pg} \mathrm{m}^{-3}$ for PCB-118 in $\left.\mathrm{PM}_{10}\right){ }^{31}$ In Taiyuan, a total of 144 particle-bound PCB congeners were identified and the total PCB mass concentrations ranged from 27 to 149 pg m${ }^{-3}$ (median $46 \mathrm{pg} \mathrm{m}^{-3}$ ) in $\mathrm{PM}_{2.5}$, and from 16 to 190 $\mathrm{pg} \mathrm{m}^{-3}$ (median $49 \mathrm{pg} \mathrm{m}^{-3}$ ) in $\mathrm{PM}_{10}{ }^{31}$ Similar mass concentrations of particle-bound PCBs (sum of 37 congeners) ranging from 17 to $168.4 \mathrm{pg} \mathrm{m}^{-3}$ (median $79.7 \mathrm{pg} \mathrm{m}^{-3}$ ) in $\mathrm{PM}_{2.5}$ and from 30.1 to $150.9 \mathrm{pg} \mathrm{m}^{-3}$ (median $78.3 \mathrm{pg} \mathrm{m}^{-3}$ ) in $\mathrm{PM}_{10}$ were determined in Beijing (China) in 2002/2003. ${ }^{30}$ Mass concentrations of particle-bound PCBs (144 congeners) measured in 2012 in Linfen and Datong, two other highly industrialized China's metropolises, were lower than those in Taiyuan and Beijing. ${ }^{33}$ The median concentrations in Linfen were $21.58 \mathrm{pg} \mathrm{m}^{-3}$ in $\mathrm{PM}_{2.5}$ and $11.9 \mathrm{pg} \mathrm{m}^{-3}$ in $\mathrm{PM}_{2.5-10}$, and in Datong 24.3 pg m ${ }^{-3}$ in $\mathrm{PM}_{2.5}$ and 17.4 in $\mathrm{PM}_{2.5-10}$.

Table 3. Mass concentrations of PCB congeners measured in weekly samples of PM10 particle fraction collected in 2000/2001 ( $N=57$ for six indicator congeners, $N=27$ for the other 11 congeners), $2002(N=52)$ and $2003(N=52)$, and $\mathrm{PM}_{2.5}$ particle fraction collected in $2010(N=22)$

\begin{tabular}{|c|c|c|c|c|c|c|c|c|c|c|c|c|}
\hline \multirow{3}{*}{ Compound } & \multicolumn{3}{|c|}{ Year 2000/2001 } & \multicolumn{3}{|c|}{ Year 2002} & \multicolumn{3}{|c|}{ Year 2003} & \multicolumn{3}{|c|}{ Year 2010} \\
\hline & \multirow{2}{*}{$n$} & \multicolumn{2}{|c|}{$\gamma / \mathrm{pg} \mathrm{m}^{-3}$} & \multirow{2}{*}{$n$} & \multicolumn{2}{|c|}{$\gamma / \mathrm{pg} \mathrm{m}^{-3}$} & \multirow{2}{*}{$n$} & \multicolumn{2}{|c|}{$\gamma / \mathrm{pg} \mathrm{m}^{-3}$} & \multirow{2}{*}{$n$} & \multicolumn{2}{|c|}{$\gamma / \mathrm{pg} \mathrm{m}^{-3}$} \\
\hline & & Range $^{(a)}$ & $\operatorname{Median}^{(\mathrm{a})}$ & & Range $^{(a)}$ & $\operatorname{Median}^{(\mathrm{a})}$ & & Range $^{(\mathrm{a})}$ & $\operatorname{Median}^{(\mathrm{a})}$ & & Range $^{(a)}$ & $\operatorname{Median}^{(a)}$ \\
\hline PCB-28(b) & 40 & $0.64-81.0$ & 21.44 & 34 & $0.50-101$ & 7.18 & 50 & $0.16-36.1$ & 8.02 & 1 & 1.27 & \\
\hline PCB-52 (b) & 26 & $0.66-5.32$ & 2.21 & 23 & $0.06-5.65$ & 1.29 & 37 & $0.09-14.7$ & 0.97 & 5 & $0.30-0.86$ & 0.75 \\
\hline PCB-60 & 12 & $0.53-1.52$ & 1.04 & 33 & $0.08-14.4$ & 5.25 & 26 & $0.06-18.0$ & 7.87 & 2 & $0.92-1.17$ & 1.05 \\
\hline PCB-74 & 6 & $0.18-16.2$ & 3.88 & 18 & $0.39-35.8$ & 1.75 & 14 & $0.88-8.13$ & 1.88 & 9 & $0.15-2.13$ & 0.70 \\
\hline PCB-101(b) & 3 & $12.4-32.8$ & 22.80 & 30 & $1.13-76.3$ & 10.60 & 45 & $0.30-27.6$ & 7.15 & 4 & $0.22-1.73$ & 0.63 \\
\hline PCB-105 & 5 & $0.98-4.92$ & 2.16 & 8 & $0.29-2.49$ & 1.19 & 5 & $0.08-2.79$ & 1.48 & 1 & 0.33 & \\
\hline PCB-114 & 9 & $0.54-7.30$ & 1.19 & 6 & $0.06-1.79$ & 0.98 & 8 & $0.32-3.45$ & 0.72 & 11 & $0.07-3.73$ & 0.32 \\
\hline PCB-118 & 26 & $0.56-10.2$ & 4.21 & 22 & $0.54-11.8$ & 3.91 & 24 & $0.92-23.64$ & 5.60 & 1 & 0.59 & \\
\hline PCB-123 & 1 & 0.51 & & 11 & $0.24-5.13$ & 1.59 & 12 & $0.15-5.40$ & 1.22 & 2 & $0.04-0.19$ & 0.12 \\
\hline PCB-138(b) & 25 & $0.87-9.53$ & 2.58 & 24 & $0.15-5.76$ & 2.29 & 35 & $0.08-10.8$ & 1.04 & 10 & $0.31-1.98$ & 0,78 \\
\hline PCB-153(b) & 14 & $1.49-10.5$ & 4.07 & 23 & $0.09-2.83$ & 1.40 & 48 & $0.12-2.65$ & 0.71 & 8 & $0.16-5.44$ & 1.91 \\
\hline PCB-156 & 10 & $1.00-5.10$ & 3.26 & 3 & $1.65-3.67$ & 3.34 & 10 & $0.50-4.14$ & 1.98 & 6 & $0.11-1.13$ & 0,26 \\
\hline PCB-157 & 8 & $1.15-3.81$ & 2.59 & 20 & $0.28-7.17$ & 1.96 & 24 & $0.09-5.34$ & 1.72 & 0 & & \\
\hline PCB-167 & 5 & $0.38-3.82$ & 1.07 & 0 & & & 5 & $0.08-1.08$ & 0.93 & 10 & $0.12-0.90$ & 0.49 \\
\hline PCB-170 & 8 & $0.54-3.79$ & 2.17 & 1 & 2.91 & & 13 & $0.94-6.21$ & 3.40 & 20 & $0.63-4.62$ & 0.87 \\
\hline PCB-180(b) & 7 & $0.45-2.06$ & 0.73 & 29 & $0.04-3.07$ & 0.43 & 17 & $0.02-3.55$ & 0.53 & 6 & $0.09-0.73$ & 0.15 \\
\hline PCB-189 & 4 & $0.81-2.11$ & 1.30 & 0 & & & 0 & & & 2 & $0.13-0.32$ & 0.22 \\
\hline
\end{tabular}

$N$ - number of analysed samples, $n$ - number of positive samples.

(a) ranges and median values apply to positive samples.

(b) PCB indicator congeners. 
Seasonal Variations in Levels of Particle-bound OC Compounds

The measurements of OC pollutants in air samples collected in 1999/2000 and 2007/2008 at the same sampling location as in the present study, indicated an increase in the mass concentrations of OC pesticides and PCBs (sum of 20 congeners) with temperature. ${ }^{19,39}$ The only exception was HCB with higher concentrations measured in winter.

Seasonal variations in concentrations of particlebound OC compounds in air were tested by correlating OC pesticide and PCB congener mass concentrations and average air temperatures measured during the 161 sampling weeks from 2000 to 2003 and the 22 sampling weeks in 2010. In the period from 2000 to 2003, the average weekly temperatures ranged from $-7.6^{\circ} \mathrm{C}$ to $25.8^{\circ} \mathrm{C}$ (median $11.1^{\circ} \mathrm{C}$ ) and in 2010 from $-4.3^{\circ} \mathrm{C}$ to $27.3^{\circ} \mathrm{C}$ (median $11.3^{\circ} \mathrm{C}$ ). In contrast to previous findings in air (vapour plus particulate phase) samples, ${ }^{19,39} \mathrm{a}$ decreasing, but for most compounds statistically nonsignificant, trend of particle-bound pollutant concentrations with increasing temperatures was observed in both sampling periods. The Spearman's rank correlation coefficients indicated a significant negative correlation of average weekly air temperatures and concentrations of particle-bound $\beta-\mathrm{HCH}, 4,4^{\prime}-\mathrm{DDE}, 4,4^{\prime}-\mathrm{DDT}$, PCB74, PCB-105, PCB-114, PCB-138, PCB-156, PCB-170 and $\mathrm{PCB}-180$ ( $r_{\mathrm{s}}$ from -0.194 to -0.389 ) in the period between 2000 and 2003 and $\gamma$-HCH, 4,4'-DDE, PCB-74, PCB-101, PCB-153, PCB-156, PCB-180 and the sum of six indicator PCBs $\left(r_{\mathrm{s}}\right.$ from -0.428 to -0.913$)$ in 2010 . However, the mass concentrations of $\mathrm{PM}_{10}$ and $\mathrm{PM}_{2.5}$ particle fractions were also significantly decreasing with increasing air temperatures $\left(r_{\mathrm{s}}=-0.614\right.$ for 2000 to $2003, r_{\mathrm{s}}=-0.830$ for $\left.2010 ; p<0.05\right)$. In weekly samples collected from 2000 to 2003, the air mass concentrations of $\mathrm{PM}_{10}$ ranged from 3.83 to $98.41 \mu \mathrm{g} \mathrm{m} \mathrm{m}^{-3}$ (median $28.88 \mu \mathrm{g} \mathrm{m}^{-3}$ ). The highest value was measured at $-7.6{ }^{\circ} \mathrm{C}$ and the lowest at $21.6^{\circ} \mathrm{C}$. Similarly, in 22 weekly $\mathrm{PM}_{2.5}$ samples collected in 2010, the particle mass concentrations were in the range of 8.73 to $72.00 \mu \mathrm{g} \mathrm{m}^{-3}$ (median $20.70 \mu \mathrm{g} \mathrm{m}^{-3}$ ). The highest and the lowest value of $\mathrm{PM}_{2.5}$ concentration was measured at $-4.3{ }^{\circ} \mathrm{C}$ and 20.1 ${ }^{\circ} \mathrm{C}$, respectively.

The air mass concentrations of $\mathrm{PM}_{2.5}$ particlebound $\gamma-\mathrm{HCH}$ and the sum of the six particle-bound indicator PCBs vs. average weekly air temperatures measured during the 2010 sampling period are shown as examples in Figure 4. The significant negative dependence of particle concentrations on air temperatures suggests that a decrease of $\mathrm{OC}$ compound concentrations was more related to the lower particle mass concentrations in air during the warm period than to the seasonal variations in mass fraction levels of compounds associated with particles. This finding was additionally supported by straight lines with slopes not significantly different than zero obtained by correlation of $\gamma-\mathrm{HCH}$ and $\Sigma 6 \mathrm{PCB}$ mass fractions in particles with air temperature. Unlike these results, $\mathrm{Xu}$ et al. ${ }^{30}$ reported a negative correlation between the $\log$ concentrations of several OC pesticides measured in $\mathrm{PM}_{2.5}$ collected in Beijing (China) and reciprocal air temperatures, which indicated increasing OC pesticide concentrations in $\mathrm{PM}_{2.5}$ particles with increasing temperature. However, the $\mathrm{PM}_{2.5}$ concentrations measured in Beijing from May 2002 to April 2003 (32.9 to $185.2 \mu \mathrm{g} \mathrm{m}^{-3}$, median $88.2 \mu \mathrm{g} \mathrm{m}^{-3}$ ) were considerably higher than concentrations measured in Zagreb and their seasonal variations were much less pronounced. Chrysikou and Samara ${ }^{29}$ observed a significant negative correlation with temperature only for the 0.95 to $1.5 \mu \mathrm{m}$ fraction of airborne particles collected in
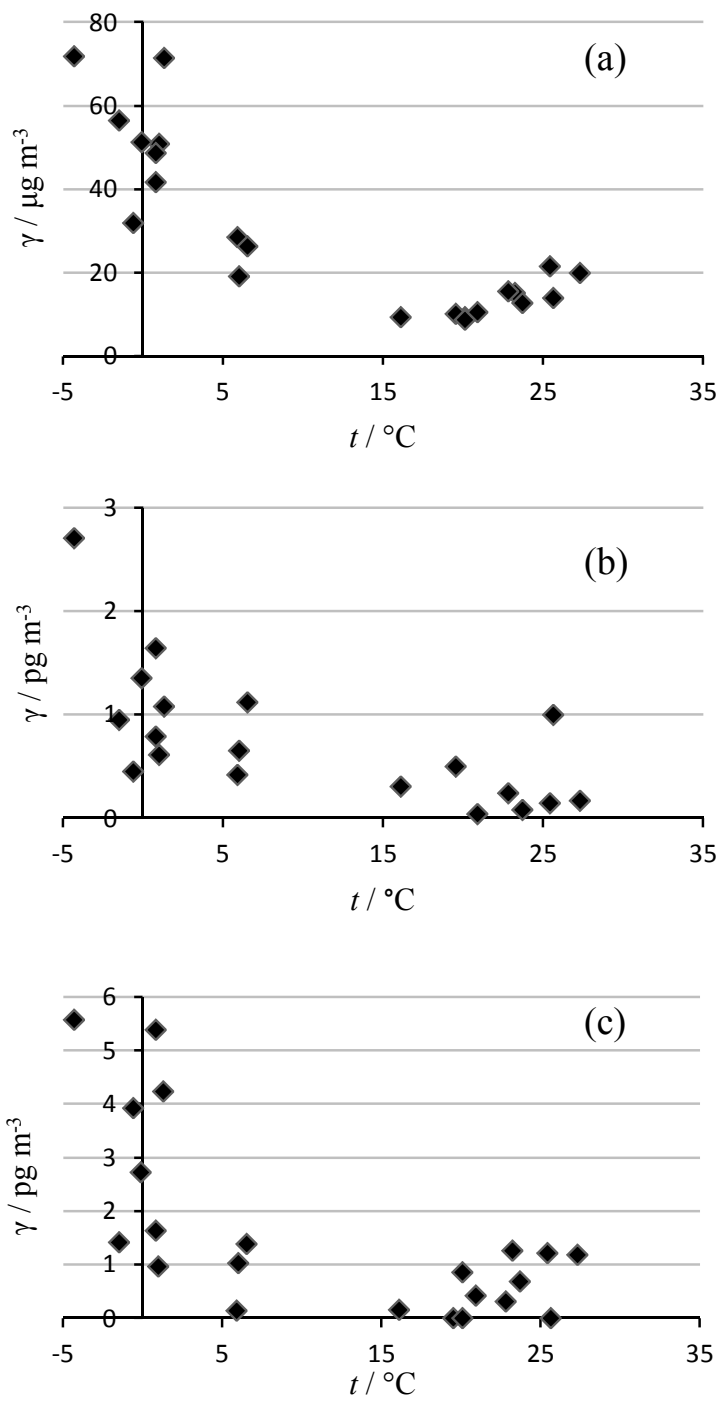

Figure 4. Correlations of average weekly air temperatures and air mass concentrations of $\mathrm{PM}_{2.5}$ particle fraction (a), particlebound $\gamma-\mathrm{HCH}(\mathrm{b})$, and the sum of the six particle-bound indicator PCBs (c) measured in 2010. 
Thessaloniki (Greece), implying increased emission and/or formation rates for particles of this size range in the cold season. However, the concentrations of OC pesticides and indicator PCBs in the sum of five collected particle fractions $(<0.95,0.95$ to $1.5,1.5$ to 3.0 , 3.0 to 7.5 and $>7.5 \mu \mathrm{m}$ ) were higher in summer than in winter. The highest proportions of target OC pollutants were found in both seasons on particles $<0.9 \mu \mathrm{m}$, but for some, increased proportions on the larger particle sizes were also observed in summer.

\section{CONCLUSION}

Mass concentrations of OC pesticides and PCBs in atmospheric $\mathrm{PM}_{10}$ and $\mathrm{PM}_{2.5}$ particle fractions collected in Zagreb between 2000 and 2003 and in 2010 were characteristic of the global environmental pollution and showed a decreasing trend. Concentrations of all compounds were considerably lower in 2010 than in earlier years and, for most compounds, followed by a lower frequency of appearance.

A local input was indicated only for $\gamma-\mathrm{HCH}$ as a consequence of its local usage before it was banned for use in agriculture and forestry in 2005 . In relation to the total number of analysed samples, the percent of particle samples in which 4,4'-DDE/4,4'-DDT mass concentration ratio was below 1 , decreased from over $40 \%$ in the period from 2000 to 2003 to below $10 \%$ in 2010 . However, these findings indicate a low but constant input of 4,4'-DDT in the atmosphere.

There were no pronounced seasonal variations in the mass fraction levels of any pesticide or PCB in airborne particles. In addition to enhanced volatilisation to gaseous phase at higher ambient temperatures, the trend of pollutant mass concentrations decreasing as air temperature increases could account for the concurrent significant decrease in particle concentrations, and, consequently, for a decrease in particle-bound OC compounds in the atmosphere.

Acknowledgements. This work was supported by the Ministry of Science, Education and Sports of the Republic of Croatia through Projects No. 0022002, 0022003, 022-0222882-2271, and 022-0222882-2896.

\section{REFERENCES}

1. S. Ubl, M. Scheringer, A. Stohl, J.F. Burkhart, and K. Hungerbuhler, Atmos. Environ. 62 (2012) 391-399.

2. C. Galbán-Malagón, A. Cabrerizo, G. Caballero, and J. Dachs, Atmos. Environ. 80 (2013) 41-49.

3. A. Di Guardo, S. Zaccara, B. Cerabolini, M. Acciarri, G. Terzaghi, and D. Calamari, Chemosphere 52 (2003) 789-797.

4. C. Poon, I. Gregory-Eaves, L. A. Connell, G. Guillore, P. M. Mayer, J. Ridal, and J. M. Blais, Environ. Toxicol. Chem. 24 (2005) 3153-3158.
5. P. Růžičková, J. Klánová, P. Čupr, G. Lammel, and I. Holoubek, Environ. Sci. Technol. 42 (2008) 179-185.

6. A. Dvorská, G. Lammel, and I. Holoubek, Atmos. Environ. 43 (2009) 1280-1287.

7. J. Paasivirta and S. I. Sinkonnen, J. Chem. Eng. Data 54 (2009) 1189-1213.

8. W. A. Ockenden, K. Breivik, S. N. Meijer, E. Steinnes, A. J. Sweetman, and K. C. Jones, Environ. Pollut. 121 (2003) 75-80.

9. P. Chakraborty, G. Zhang, S. Eckhardt, J. Li, K. Breivik, P. K. S. Lam, S. Tanabe, and K. C. Jones, Environ. Pollut. 182 (2013) 283-290.

10. J. He, R. Balasubramanian, S. Karthikeyan, and U. M. Joshi, Chemosphere 75 (2009) 640-648.

11. M. Mandalakis, M. Tsapakis, A. Tsoga, and E. G. Stephanou, Atmos. Environ. 36 (2002) 4023-4035.

12. M. Mandalakis and E. G. Stephanou, Environ. Pollut. 147 (2007) 211-221.

13. B. Cetin, S. Yatkin, A. Bayram, and M. Odabasi, Chemosphere 69 (2007) 1267-1277.

14. C. Coscollà, P. Colin, A. Yahyaoui, O. Petrique, V. Yusà, A. Mellouki, and A. Pastor, Atmos. Environ. 44 (2010) 3915-3925.

15. G. Lammel, Y-S. Ghim, A. Grados, H. Gao, H. Hühnerfuss, and R. Lohmann, Atmos. Environ. 41 (2007) 452-464.

16. G. Lammel, J. Klánova, Lj. Erić, P. Ilić, J. Kohoutek, and I. Kovačić, J. Environ. Monitor. 13 (2011) 3358-3364.

17. A. Scheyer, S. Morville, P. Mirabel, and M. Millet, Atmos. Environ. 41 (2007) 3604-3618.

18. S. Herceg Romanić and B. Krauthacker, Bull. Environ. Contam. Toxicol. 64 (2000) 811-816.

19. S. Herceg Romanić and B. Krauthacker, Bull. Environ. Contam. Toxicol. 71 (2003) 1034-1041.

20. A. Bozlaker, A. Muezzinoglu, and M. Odabasi, Chemosphere 77 (2009) 1168-1176.

21. S. Siddik Cindoruk, Chemosphere 82 (2011)78-87.

22. A. Scheyer, C. Graeff, S. Morville, P. Mirabel, and M. Millet, Chemosphere 58 (2005) 1517-1524.

23. M. Sadiki and L. Poissant, Atmos. Environ. 42 (2008) 8288-8299.

24. J. Klánová, J. Kohoutek, R. Kostrhounová, and I. Holoubek, Environ. Intern. 33 (2007) 719-726.

25. K-H. Kim, E. Kabir, and S. Kabir, Environ. Intern. 74 (2015) 136-143.

26. W-J. Lee, C-C. Su, H-L. Sheu, Y-C. Fan, H-R. Chao, and G-C. Fang, J. Hazard. Mater. 49 (1996) 57-88.

27. H. Kaupp and M. S. McLachlan, Atmos. Environ. 34 (2000) 73-83.

28. M. Mandalakis and E. G. Stephanou, Environ. Toxicol. Chem. 21 (2002) 2270-2275.

29. L.P. Chrysikou and C.A. Samara, Atmos. Environ. 43 (2009) 4557-4569.

30. D. Xu, M. Dan, Y. Song, Z. Chai, and G. Zhuang, Atmos. Environ. 39 (2005) 4119-4128.

31. S. Fu, H-X. Cheng, Y-H. Liu, Z-Z. Yang, and X-B. Xu, Chemosphere 74 (2009) 1477-1484.

32. S. Fu, H-X. Cheng, Y-H. Liu, and X-B. Xu, Chemosphere 75 (2009) 588-594.

33. H. Nie, S. Fu, Y. Dong, and Z. Yang, Chemosphere 114 (2014) 210-218.

34. B. Krauthacker, S. Herceg Romanić. M. Wilken, and Z. Milanović, Chemosphere 62 (2006) 1829-1837.

35. T. Bartoš, P. Čupr, J. Klánová, and I. Holoubek, Environ. Intern. 35 (2009) 1066-1071.

36. EN 12341:1998: Air quality - Determination of the PM10 fraction of suspended particulate matter -Reference method and field test procedure to demonstrate reference equivalence of measurement methods. 
37. I. Bešlic, K. Šega, and Z. Bencetić Klaić, EURASAP Newsletter 53, (2004)

38. EN 14907:2005 - Ambient air quality - Standard gravimetric measurement method for the determination of the PM2.5 mass fraction of suspended particulate matter.

39. D. Klinčić, Air pollution and bioindicators of human and marine organism exposure to persistent organochlorine compounds. Doctoral Thesis, Faculty of Science, University of Zagreb, 2012, pp. 81-93.

40. D. Kožul and S. Herceg Romanić, Bull. Environ. Contam. Toxicol. 81 (2008) 339-342.

41. S. Herceg Romanić and B. Krauthacker, Fresenius Environ. Bull. 12 (2003) 143-147. 